\title{
Experimental Research on Flow Development and Control Effectiveness in the Duct at High Speed
}

\author{
S. A. Khan, Zaheer Ahmed, Abdul Aabid, Imran Mokashi
}

Keywords-Wall pressure, L/D ratio, NPR, Mach Number.

\section{INTRODUCTION}

The application of missiles and rockets has amplified exponentially in the present scenario. But still, the difficulty in aerodynamics involved with respect to these vehicles is a challenge. The critical problem is high-pressure related to the shock wave in front, and low-pressure recirculation developed behind the vehicle at the corner base. This barrier of wave drags due to the shock waves, and the drag due to the bubble leads to a massive amount of the fuel consumption and high variations in the flow-field of the sudden expansion duct. As there exists broad applicability of sudden expansion flows, this study thus is related to control of base pressure in such flows. While scanning the literature, it is observed that the primary focus has been to control the base flow field through the passive control where there is a need for geometrical changes in the experimental setup, with a marginal increase in the weight of the system without sacrificing the on the performance parameters. However, in the case of active control, there is a need for an external source of energy, which is a significant concern, and in most of the cases, it is challenging. But in the present case, an attempt is made to use the active methods to regulate the sudden expansion flow field and hence assess the effectiveness of the control mechanism. Since we are utilizing the air from the primary storage chamber of the

Revised Manuscript Received on August 19, 2019.

S. A. Khan,Mechanical Engineering Dept. Faculty of Engineering, IIUM Kuala Lumpur, Malaysia (sakhan@iium.edu.my)

Zaheer Ahmed,Mechanical Engineering Dept. Faculty of Engineering, IIUM Kuala Lumpur, Malaysia

Abdul Aabid,Mechanical Engineering Dept. Faculty of Engineering, IIUM Kuala Lumpur, Malaysia

Imran Mokashi,Mechanical Engineering Dept. Faculty of Engineering, IIUM Kuala Lumpur, Malaysia

\begin{abstract}
This paper presents an experimental study of suddenly expanded flows at supersonic speed is performed. A Convergent-divergent (C-D) nozzle is used with suddenly expanded duct. At the recirculation zone, the pressure is controlled by using four microjets of $1 \mathrm{~mm}$ diameter arranged at PCD of 1.3 as an active control mechanism to regulate the pressure in the wake region. The development and the quality of the flow were monitored to ensure that the flow control does not aggravate the flow field in the duct. The geometrical and the inertia parameters are the area ratio and the Mach number. The area of the study was 3.24, L/D ratio was from 10 to 1 , and the level of inertia as 2.1. The expansion level considered during the experiments was from 3 to 11 . The results clearly indicate that the wall pressure variation with and without control in the enlarged duct does not vary, which means that the use of control does not affect the flow filed in the circular duct.
\end{abstract}

experimental setup; hence, the requirement of the additional source of energy is eliminated/ruled out.

There are numerous researchers used the passive control methods to maneuver the flow field, and thebase pressure with and few of them which are related to the present work are reviewed in the below section.

\section{LITERATURE SURVEY}

Khan et al., [1] experimentally investigated the effectiveness of the microjets in the convergent-divergent axis-symmetry nozzle with the duct. Along a pitch circle diameter if 1.3 times the diameter of the nozzle at the exit, four micro jests were placed. The angular position of each other was ninety degrees in a cross position. These four tiny jets were like an active control mechanism of the flow as well as the base pressure. The quality of the flow field in the duct and the magnitude of the static pressure at the duct wall compared with active and no control of the investigations. Their results indicated clearly that in the selected Mach number and NPR by selecting proper length to diameter ratio of the duct and diameter of the duct, one can get a significant increase in the base pressure.

Along with this analysis, the wall pressure in the duct was also measured in Ref. [2], experimentally investigation efficiency of the microjet controller for a convergentdivergent nozzle with the suddenly expanded duct. control the base pressure, four microjets of $1 \mathrm{~mm}$ orifice diameter at the base, nozzle symmetry axis was employed in the form of active control. Besides, the wall pressure distribution along the suddenly expanded duct length was investigated. Their results indicated that in the selected Mach number and the level of expansion employed to the jets and by selecting the proper length to diameter ratio of the duct and the step height of the duct, one could get a considerable increase/decrease in the base pressure values in the base region.

In Ref. [3], an experimental method was used to investigate the efficiency of microjets controller at the base of the convergent-nozzle. The jets at all Mach numbers were correctly expanded. From the results, it shows that the microjets can control the pressure at the base called base pressure active control and proved that the wall pressure distribution is not adversely influenced by the microjets [4].

To move on this type of study, in Ref. [5] experimentally investigation have been found, to study the microjets affects to control base pressure in enlarged axisymmetric ducts. The wall pressure variation along the smooth duct was calculated

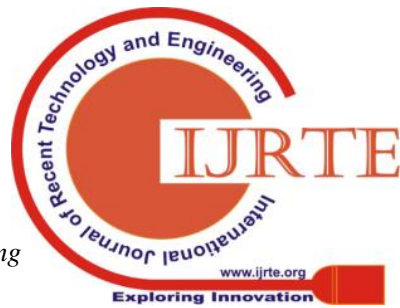


and declared that the microjets can behave as real controllers for base pressure. Moreover, the wall pressure distribution is not adversely influenced by the microjets.

In Ref. [6], investigated experimentally investigated the usefulness of microjets under the influence of the active control in the form of the tinyjets at all the possible level of the expansions which usually takes place in the case C-D nozzles to control the base pressure in suddenly expanded axisymmetric ducts. From the wind tunnel tests, they found that the maximum increment in the pressure at the base is one hundred and fifty-two percent for Mach number 2.58, and the microjets do not negativelyaffect the flow field and the pressure of the duct wall. Also, it shows that microjets can serve as an active regulator of the flow, raising the base pressure on either side for some combination for the flow and geometric parameters.

The base pressure control in a sudden expansion of an axisymmetric duct and the flow field is not adversely affected by the control mechanism, and the issues related on the internal supersonic flow has been conducted experimentally [7] and particularly for area ratio 7.56 [8]. The flow of gas from the nozzle expanded into the duct of the circular pipe having sufficiently large cross-section than the nozzle exit area. In the duct, the development of flow was also studied. In this work, the investigation provided that active control can serve in increasing the base pressure for the case when relief to the flow is significant [9].

Khan et al., [10]-[12] investigated the number of experimental studies for the base pressure control in a CD nozzle and the effectiveness of the tiny jets as a control mechanism. Also, the nature of the flow the duct length, as well as its magnitude with and without regulations, is unchanged. Influence of microjet control for different area ratio's well studied by the authors [14]-[17]. Experimentally investigated the cylindrical effects of base pressure control using active and passive method [18]-[22].

The computational fluid dynamics method using ANSYS FLUENT [23] commercial code some investigations have been found from last decades few of them are specified here. An ANSYS simulation was conducted to assess the effectiveness of tiny jets to regulate the base pressure in suddenly expanded 2-D convergent-divergent nozzle. The CD nozzle was modeled, and the numerically simulated using turbulence models: K- $\varepsilon$ turbulence model from the code was used with the CFDsoftware [24]-[29].

Also, some studies found the density-based solution [30][36]. CFD method is also used to simulate the supersonic flow over the wedge [37], [38]. Simulated the non-circular cylinder to find the drag formation by varying the inlet velocity [39]. From the above literature, it has been observed there is no work stated with active control effect of wall pressure distribution for Mach number 2.1 and area ratio 3.24. Therefore, in this investigation, an attemptis made to investigate the wall pressure values with and without control for under expanded jets exiting from the CD nozzle.

\section{EXPERIMENTAL INVESTIGATION}

\section{Experimental Set-up}

Fig. 1 shows the essential features of sudden expansion flow filed showing the reattachment point, expansion waves, and recirculation zone. The same concept is used to perform the experimental investigation with the application of four microjets at the base, as shown in Fig. 2 demonstrates the setup used for the present investigations, which is also discussed in [1]. This was performed by utilizing the experimental setup of Fig. 2, which is made up of pipelines, the storage tank, the settling chamber, and the pressure transducers. The air can pass through the required values regulated and later adequately through the model of the present investigations. The nozzle is an attached with a duct the experimental setup. The flow expanding from the nozzle and reaching the end downstream of the duct is exposed to the ambient atmospheric pressure. Fig. 3 show the remaining arrangement involved in the setup. At the nozzle exit and base of the duct $1 \mathrm{~mm}$ holes, eight in number are arranged to blow jet using 4 holes at the base corner of the flow. The remaining four holes are for the pressure measurement at the base. Along the length of the duct, the wall pressure taps are provided to measure and record the pressure along the duct wall when the flow is exhausted into the duct. The pressure range is the $0-15$ bar of the transducer employed, and it has 16 channels. The sampling rate of the pressure transducer is 250 samples per second, and then the reading area-averaged, and then they are displayed on the monitor of the desktop PC and recorded. The wall pressure was recorded using multi-tube mercury manometer.

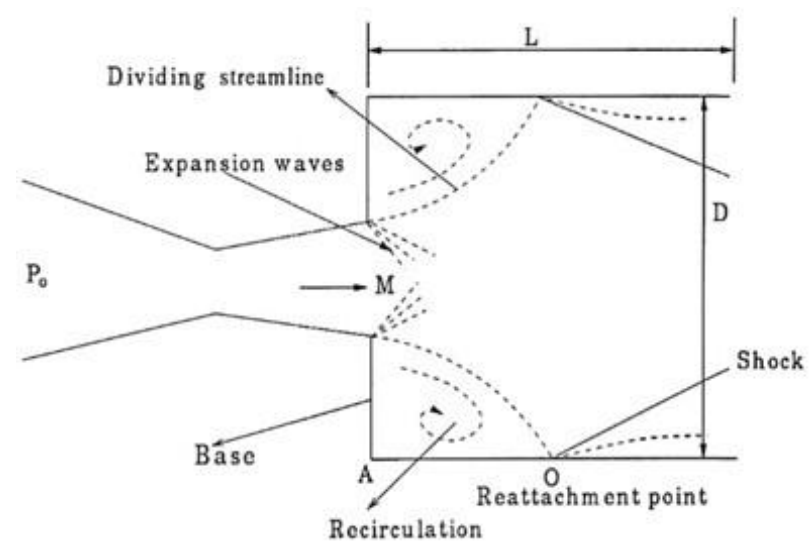

Fig. 1. A view of the Flow Field from C-D Nozzle.

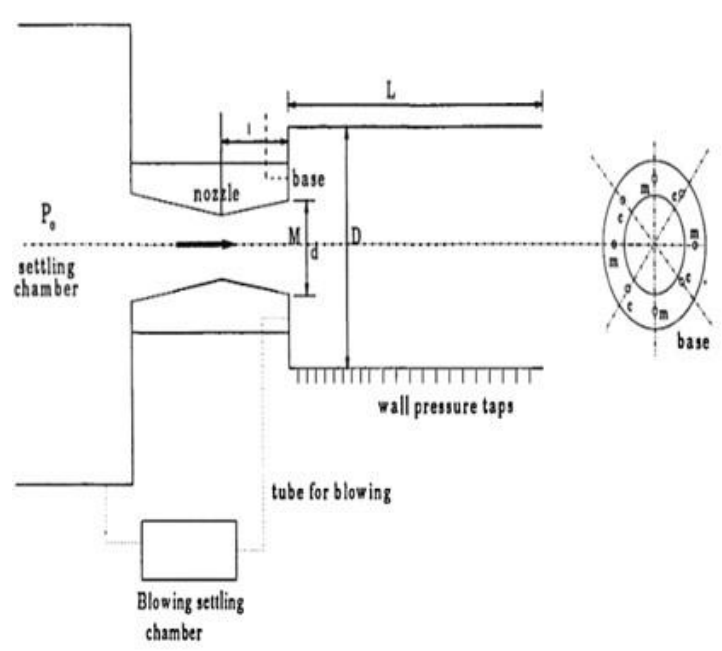

Fig. 2. Wind tunnel test Setup.

Published By:

Blue Eyes Intelligence Engineering 


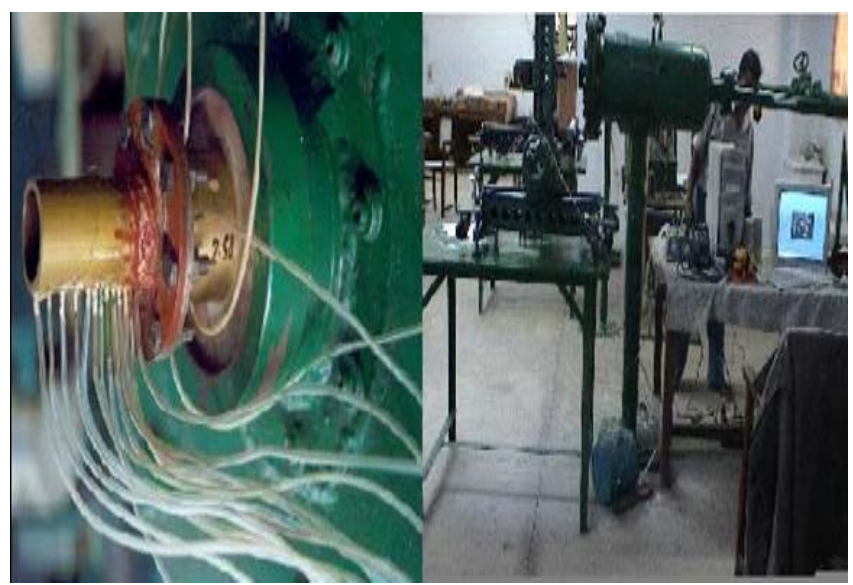

Fig. 3. A View of Suddenly Expanded Duct with Pressure Tapings and setup location

\section{RESULTS AND DISCUSSION}

Fig. 4 present the flow development and its behavior in the enlarged duct for area ratio 3.24 , for some selected combination of Inertia levels. For this area ratio of 3.24 in the case of slightly increased relief for the expanding flow.

Figs. 4 presents the results for Mach 2.1. From the results, it is seen that the results for higher Mach numbers behave differently. This trend seems to be due to the higher level of over-expansion at these NPR's. In case of lower Mach numbers, the NPRs are such that favorable pressure gradient exists, and the jets were under expanded for the most of NPR's tested, which is not the case for this Mach number. For most of the NPRs tested at this Mach numbers the Jets are over expanded. Under these circumstances, when the jets are exiting from the nozzle into the enlarged duct, the wall pressure values have minimum fluctuations as the jets are already over-expanded, and they attained higher wall pressure values. Hence the peak values are $20 \%$ above the ambient pressure. At $\mathrm{L} / \mathrm{D}=10$ and $\mathrm{M}=2.1$ the control is capable manipulating the flow to reduce the base suction and hence finally results in an increase of the pressure along the duct for most of the cases tested in the present case of the present range of NPR, and the control effectiveness is minimal. The trend which was seen at NPR 3 at lower Mach numbers this trend continues at Mach 2.1 for NPR from 3 to 7 , the reason for this trend may be same as discussed above (Figs. 4.(a)).

Fig. 4 (b) presents the similar wall pressure results for $\mathrm{L} / \mathrm{D}=8$ as was observed in the previous figure with the exception that the wall pressure magnitude has reduced considerably due to the effect of reduced duct length and flow has become smooth. Figs. 4((c) to (d)) represent the wall pressure results for $\mathrm{L} / \mathrm{D}=6$ and 5 with the exception that due the reduction in the L/D ratio there are oscillations in the wall pressure due to the influence of back pressure and the peak pressure values are less than that those were for higher $\mathrm{L} / \mathrm{D}$ ratios namely ( $\mathrm{L} / \mathrm{D}=10$ and 8 ). The oscillations in the wall pressure are for NPR's 9 and 11. It is also seen that the flow field has smoothened in the duct and wall pressure values with and without control are identical. This trend continues until $\mathrm{L} / \mathrm{D}=4$, and 3 (Figs. 4 ((e) to (f)), then later for lower $\mathrm{L} / \mathrm{Ds}$ like $\mathrm{L} / \mathrm{D}=2$ and 1 , it is seen from these results that this length of the enlarged is not sufficient for the flow to be attached with the duct wall, and it is suggested that the values for the smaller L/Ds may be ignored as they do not convey any message due to the insufficient length of the duct.

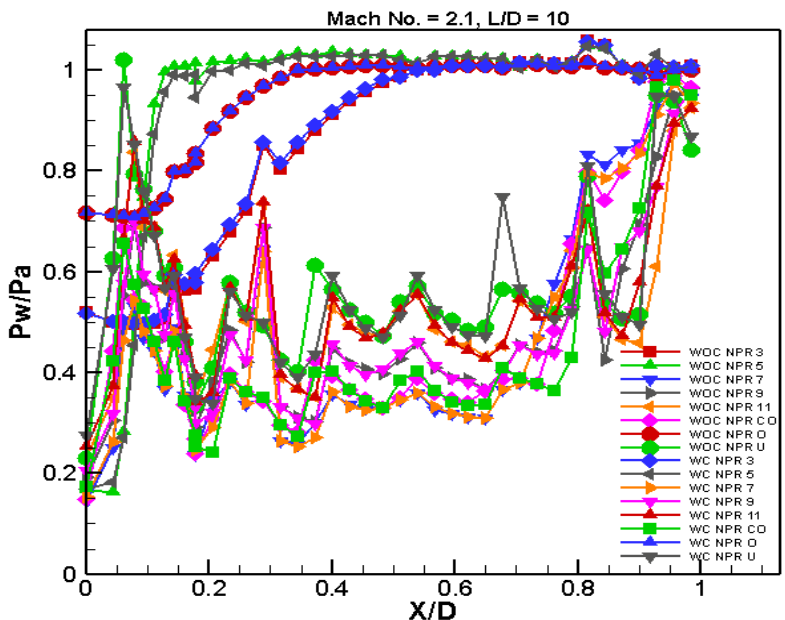

(a)

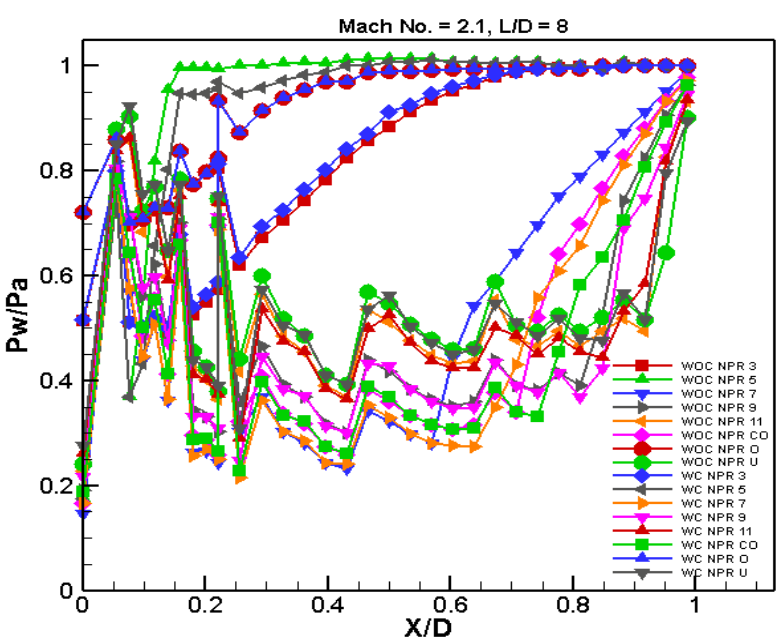

(b)

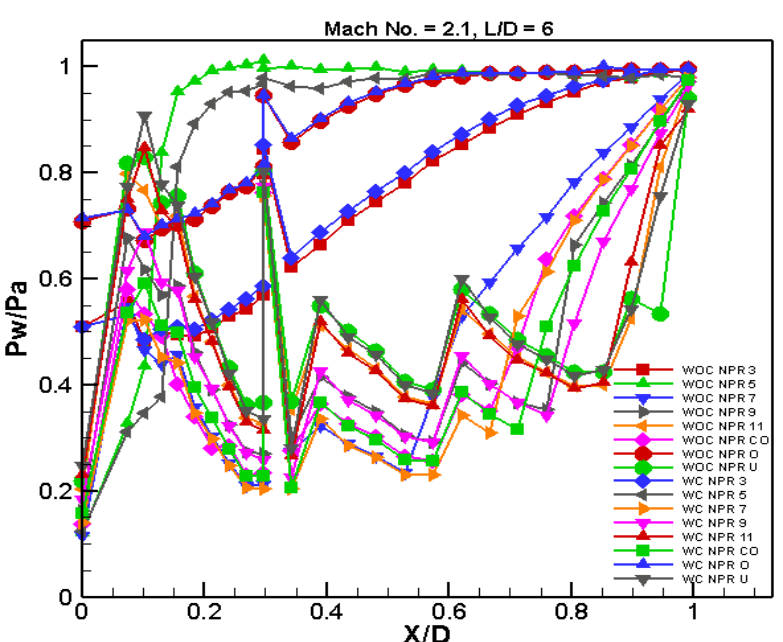

(c) 


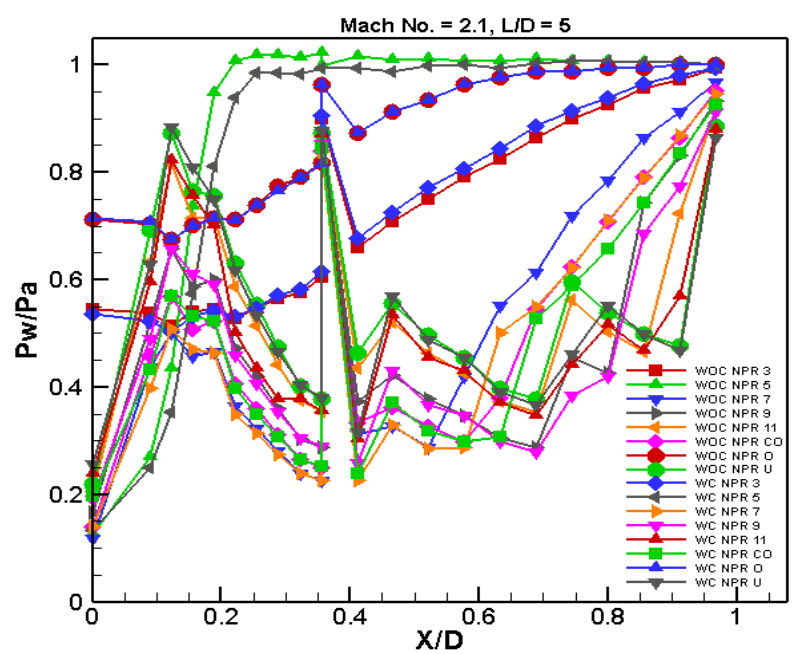

(d)

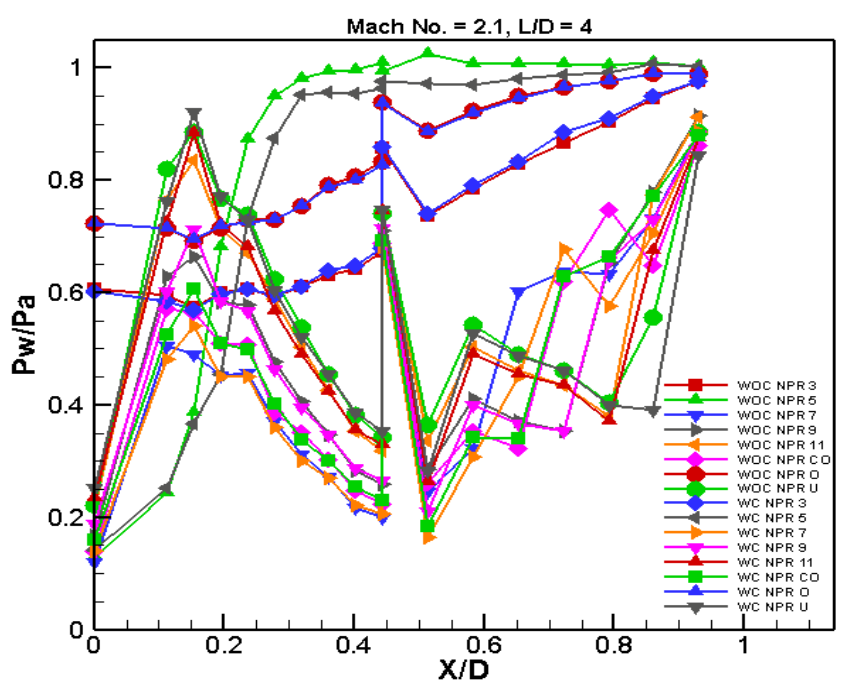

(e)

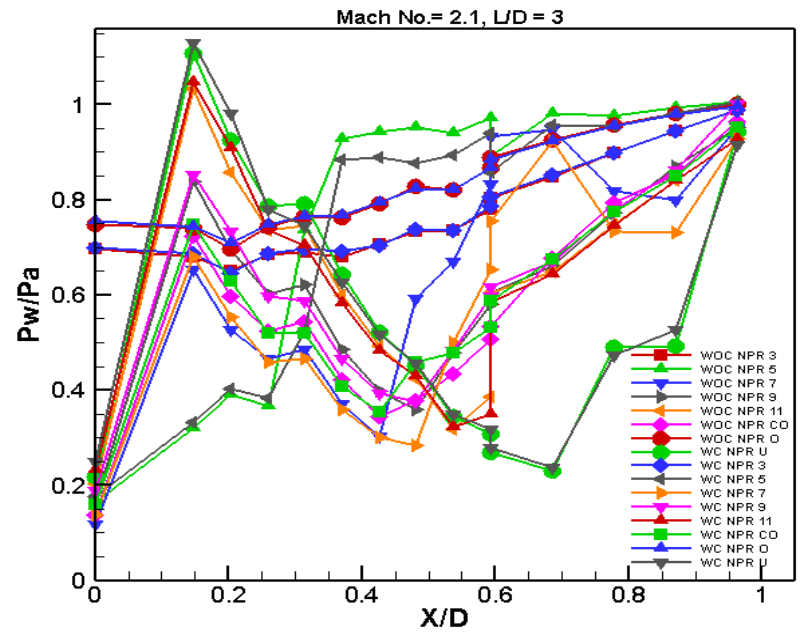

(f)

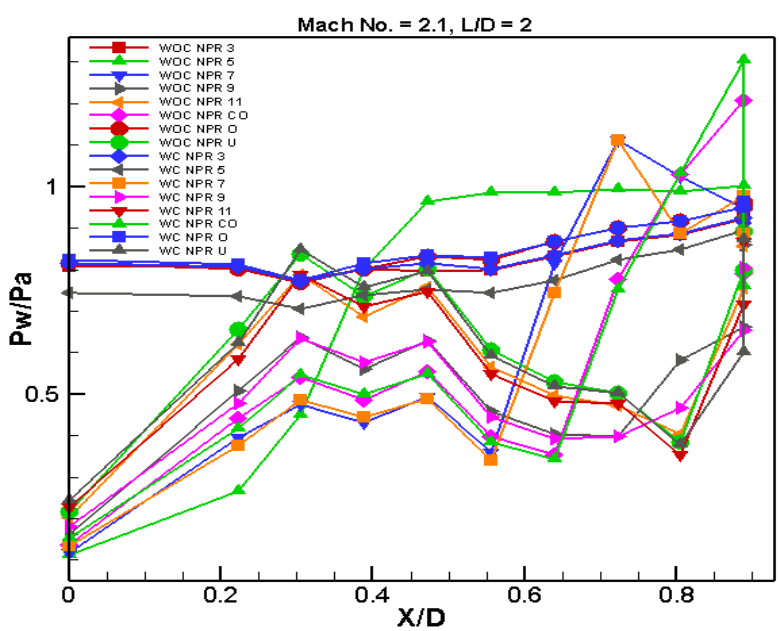

(g)

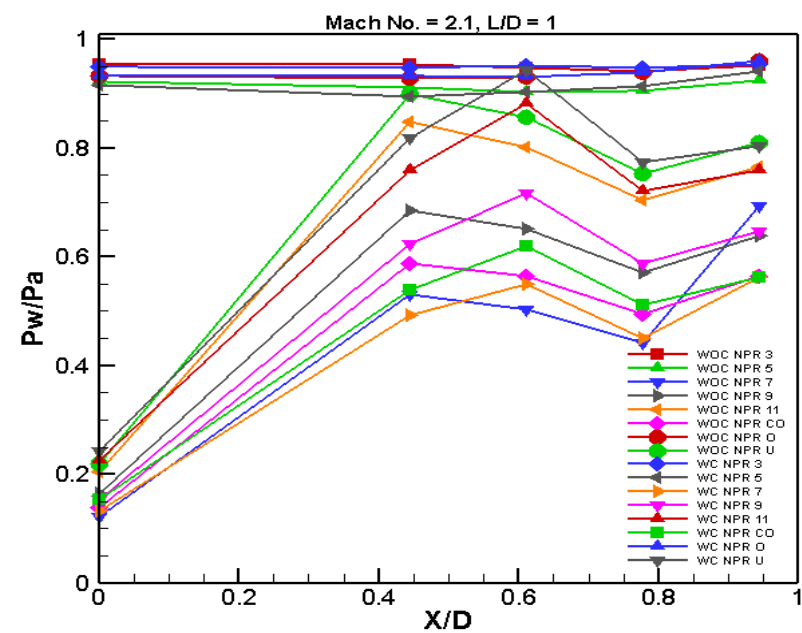

(h)

Fig. 4. Wall Pressure Vs. X/D

\section{CONCLUSION}

Based on the above discussion, we may draw the following conclusion:

- On the flow development and the quality and magnitude of the pressure at the wall in the enlarged duct at high supersonic Mach number $M=2.1$, with the cross-sectional area of duct being 3.24, is investigated experimentally.

- The flow field before and after the deployment of the control mechanism is unaltered and remained identical.

- At lower NPRs the flow is not attached with the duct for $L / D=2$. This means that for this study for the given situations, the minimum duct length needed is $\mathrm{L} / \mathrm{D}=2$ and above.

- L/D of the duct which was varied during the wind tunnel testing was in the range from 1 to 10 , and the nozzle pressure ratio (NPR) considered for the wind tunnel tests and analysis is from 3, 5, 7, 9, and 11 .

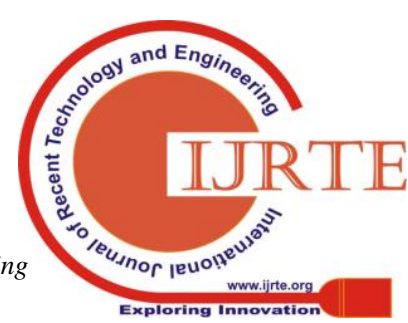


- The use of microjets resulted in a decrement of the base suction at the base region, and this decrease of the base suction resulted in an increase of the base pressure is associated with a decrement in the drag values which is very useful for these combinations of the parameters.

- The control from the tiny jet is resulting in an $83 \%$ increase in the base pressure value. Any decrease in the base pressure will result in a significant increase in the range of the aerospace vehicles and hence savings in the fossil fuels and making the operations of the flight of the aerospace vehicle more economically viable.

- Finally, active control does not aggravate the nature of the flow in the duct wall and hence the duct static wall pressure distribution. This shows that the active control using microjets is effective in controlling the base pressure and reduction of the base drag without any negative impact and any disturbance in the flow field.

\section{REFERENCES}

1. S. A. Khan and E. Rathakrishnan, "Active Control of Suddenly Expanded Flows from Overexpanded Nozzles," International Journal of Turbo and Jet Engines, vol. 19, pp. 119-126, 2002.

2. S. A. Khan and E. Rathakrishnan, "Control of Suddenly Expanded Flows with Micro-Jets," International Journal of Turbo and Jet Engines, vol. 20, pp. 63-82, 2003.

3. S. A. Khan and E. Rathakrishnan, "Active Control of Suddenly Expanded Flows from Underexpanded Nozzles," International Journal of Turbo and Jet Engines, vol. 21, pp. 233-254, 2004.

4. S. A. Khan and E. Rathakrishnan, "Control of Suddenly Expanded Flows from Correctly Expanded Nozzles," International Journal of Turbo and Jet Engines, vol. 21, pp. 255-278, 2004.

5. S. A. Khan and E. Rathakrishnan, "Active Control of Suddenly Expanded Flows from Underexpanded Nozzles Part II," International Journal of Turbo and Jet Engines, vol. 22, pp. 163-183, 2005.

6. S. A. Khan and E. Rathakrishnan, "Control of suddenly expanded flow," Aircraft Engineering and Aerospace Technology: An International Journal, vol. 78, no. 4, pp. 293 309, 2006.

7. S. Rehman and S. A. Khan, "Control of base pressure with micro-jets: part I," Aircraft Engineering and Aerospace Technology, vol. 80, no. 2, pp. 158-164, 2008.

8. F. A. G. M and S. A. Khan, "Active Control of Base Pressure using Micro Jets for Area Ratio of 7.56," Int. J. Innov. Technol. Explor. Eng., vol. 8, no. May, pp. 491-495, 2019.

9. M. A. A. Baig, S. A. Khan, and E. Rathakrishnan, "Active control of base pressure in suddenly expanded flow for area ratio 4.84,” Int. J. Eng. Sci. Technol., vol. 4, no. 05, pp. 1892 1902, 2012.

10. J. D. Quadros, S. A. Khan, and A. J. Antony, "Effect of Flow Parameters on Base Pressure in a Suddenly Expanded Duct at Supersonic Mach number Regimes using CFD and Design of Experiments," Journal of Applied Fluid Mechanics, vol. x. No. x, 2016.

11. Z. I. Chaudhary, V. B. Shinde, M. Bashir, and S. A. Khan, "Experimental Investigation on the Effectiveness of Active Control Mechanism on Base Pressure at Low Supersonic Mach Numbers," in In Innovative Design and Development Practices in Aerospace and Automotive Engineering, 2017, pp. 197-209.
12. J. D. Quadros, S. A. Khan, and A. A. J., "Modelling of Suddenly Expanded Flow Process in Supersonic Mach Regime using Design of Experiments and Response Surface Methodology," Journal of Computational Applied Mechanics, vol. 49, no. 1, pp. 149-160, 2018.

13. G. M. Fharukh Ahmed, M. A. Ullah, and S. A. Khan, "Experimental study of suddenly expanded flow from correctly expanded nozzles," ARPN Journal of Engineering and Applied Sciences, vol. 11, no. 16, pp. 10041-10047, 2016.

14. S. A. Khan, A. Aabid, and Z. I. Chaudhary, "Influence of Control Mechanism on the Flowfield of Duct at Mach 1.2 for Area Ratio 2.56," Int. J. Innov. Technol. Explor. Eng., vol. 8, no. 6S4, pp. 1135-1138, 2019.

15. M. H. Azami, M. Faheem, A. Aabid, I. Mokashi, and S. A. Khan, "Inspection of Supersonic Flows in a CD Nozzle using Experimental Method,” Int. J. Recent Technol. Eng., vol. 8, no. 2S3, pp. 996-999, 2019.

16. M. H. Azami, M. Faheem, A. Aabid, I. Mokashi, and S. A. Khan, "Experimental Research of Wall Pressure Distribution and Effect of Micro Jet at Mach," Int. J. Recent Technol. Eng., vol. 8, no. 2S3, pp. 1000-1003, 2019.

17. S. A. Khan, I. Mokashi, A. Aabid, and M. Faheem, "Experimental Research on Wall Pressure Distribution in C-D Nozzle at Mach number 1.1 for Area Ratio 3.24," Int. J. Recent Technol. Eng., vol. 8, no. 2S3, pp. 971-975, 2019.

18. S. A. Khan, M. Asadullah, and J. Sadiq, "Passive Control of Base Drag Employing Dimple in Subsonic Suddenly Expanded Flow," Int. J. Mech. Mechatronics Eng., vol. 8, no. 03, pp. 69-74, 2018.

19. S. A. Khan and M. Asadullah, "Passive Control of Base Drag in Compressible Subsonic Flow using Multiple Cavity," Int. J. Mech. Prod. Eng. Res. Dev., vol. 8, no. 4, pp. 39-44, 2018.

20. M. Asadullah, S. A. Khan, W. Asrar, and E. Sulaeman, "LowCost Base Drag Reduction Technique,” Int. J. Mech. Eng. Robot. Res., vol. 7, no. 4, pp. 428-432, 2018.

21. M. Asadullah, S. A. Khan, W. Asrar, and E. Sulaeman, "Passive control of base pressure with the static cylinder at supersonic flow," in IOP Publishing House, IOP Conf. Series: Materials Science and Engineering, 2018, pp. 1-10.

22. M. Asadullah, S. A. Khan, W. Asrar, and E. Sulaeman, "Active control of base pressure with the counter-clockwise rotating cylinder at Mach 2," 2017 4th IEEE Int. Conf. Eng. Technol. Appl. Sci., vol. 8, no. 6, pp. 1-6, 2017.

23. ANSYS Inc, "ANSYS FLUENT 18.0: Theory Guidance," Canonsburg PA, 2017.

24. S. A. Khan, A. Aabid, and M. A. A. Baig, "CFD Analysis of CD Nozzle and Effect of Nozzle Pressure Ratio on Pressure and Velocity For Suddenly Expanded Flows," International Journal of Mechanical and Production Engineering Research and Development, vol. 8, no. June, pp. 1147-1158, 2018.

25. A. Khan, A. Aabid, and S. A. Khan, "CFD analysis of convergent-divergent nozzle flow and base pressure control using micro-JETS," International Journal of Engineering and Technology, vol. 7, no. 3.29, pp. 232-235, 2018.

26. A. G. M. Fharukh, A. A. Alrobaian, A. Aabid, and S. A. Khan, "Numerical Analysis of Convergent-Divergent Nozzle Using Finite Element Method," International Journal of Mechanical and Production Engineering Research and Development, vol. 8, no. 6, pp. 373-382, 2018.

27. A. Aabid, A. Khan, N. M. Mazlan, M. A. Ismail, M. N Akhtar, and S. A. Khan, "Numerical Simulation of Suddenly Expanded Flow at Mach 2.2," International Journal of Engineering and Advanced Technology, vol. 8, no. 3, pp. 457-462, 2019.

28. S. A. Khan, A. Aabid, and C. A. Saleel, "Influence of Micro Jets on the Flow Development in the Enlarged Duct at Supersonic Mach number," International Journal of Mechanical and Mechatronics Engineering, 
vol. 19, no. 01 , pp. 70-82, 2019.

29. S. A. Khan, A. Aabid, F. A. G. M, A. A. Al-Robaian, and A. S. Alsagri, "Analysis of Area Ratio In a CD Nozzle with Suddenly Expanded Duct using CFD Method," CFD Lett., vol. 11, no. 5, pp. 61-71, 2019.

30. K. A. Pathan, P. S. Dabeer, and S. A. Khan, "Effect of nozzle pressure ratio and control jets location to control base pressure in suddenly expanded flows," J. Appl. Fluid Mech., vol. 12, no. 4, pp. 1127-1135, 2019.

31. K. A. Pathan, P. S. Dabeer, and S. A. Khan, "Optimization of Area Ratio and Thrust in Suddenly Expanded Flow at Supersonic Mach Numbers," Case Stud. Therm. Eng., 2018.

32. K. A. Pathan, P. S. Dabeer, and S. A. Khan, "Investigation of base pressure variations in internal and external suddenly expanded flows using CFD analysis," CFD Lett., vol. 11, no. 4, pp. 32-40, 2019.

33. K. A. Pathan, P. S. Dabeer, and S. A. Khan, "Influence of Expansion Level on Base Pressure and Reattachment Length," CFD Lett., vol. 11, no. 5, pp. 22-36, 2019.

34. K. A. Pathan, S. A. Khan, and P. S. Dabeer, "CFD Analysis of Effect of Area Ratio on Suddenly Expanded Flows," in 2nd International Conference for Convergence in Technology (I2CT) CFD, 2017, pp. 1192-1198.

35. K. A. Pathan, S. A. Khan, and P. S. Dabeer, "CFD Analysis of Effect of Mach number , Area Ratio and Nozzle Pressure Ratio on Velocity for Suddenly Expanded Flows," in 2nd International Conference for Convergence in Technology (I2CT) CFD, 2017, pp. 1104-1110.

36. K. A. Pathan, S. A. Khan, and P. S. Dabeer, "CFD Analysis of Effect of Flow and Geometry Parameters on Thrust Force Created by Flow from Nozzle," in 2nd International Conference for Convergence in Technology (I2CT) CFD, 2017, pp. 1121-1125.

37. S. A. Khan, A. Aabid, and C. A. Saleel, "CFD Simulation with Analytical and Theoretical Validation of Different Flow Parameters for the Wedge at Supersonic Mach Number," International Journal of Mechanical and Mechatronics Engineering, no. 01, 2019.

38. S. A. Khan, A. Aabid, I. Mokashi, A. A. Al-Robaian, and A. S. Alsagri, "Optimization of Two-dimensional Wedge Flow Field at Supersonic Mach,” CFD Lett., vol. 11, no. 5, pp. 8097, 2019.

39. M. F. M. Sajali, A. Aabid, S. A. Khan, F. A. G. M, and E. Sulaeman, "Numerical Investigation of Flow Field of a NonCircular Cylinder Numerical Investigation of Flow Field of a Non-Circular Cylinder," CFD Lett., vol. 11, no. 5, pp. 37-49, 2019. 